\title{
The Transtheoretical Model and obesity: A bibliometric study
}

\author{
ANA ANDRÉS, ${ }^{\mathrm{a}}$ JUANA GÓMEZ, ${ }^{\mathrm{a}}$ CARMINA SALDAÑA ${ }^{\mathrm{b}}$ \\ a Department of Methodology for the Behavioural Sciences, University of Barcelona, Barcelona (Spain) \\ ${ }^{\mathrm{b}}$ Department of Personality, Assessment and Psychological Treatment, University of Barcelona, \\ Barcelona (Spain)
}

The Transtheoretical Model of behaviour change is currently one of the most promising models in terms of understanding and promoting behaviour change related to the acquisition of healthy living habits. By means of a bibliographic search of papers adopting a TTM approach to obesity, the present bibliometric study enables the scientific output in this field to be evaluated. The results obtained reveal a growing interest in applying this model to both the treatment of obesity and its prevention. Otherwise, author and journal outputs fit the models proposed by Lotka and Bradford, respectively.

\section{Introduction}

The rapid rise in the prevalence of eating disorders involving overweightness and obesity has seen them become one of the key health problems in an increasing number of countries. Moreover, obesity is associated with many other diseases such as cardiovascular disorders, hypertension, type-II diabetes, certain types of cancer and sleep apnea, among others (World HEALth ORGANIZATION, 2000). To date, the strategies used to halt the progression of what is already regarded as an obesity epidemic have had little effect, thus highlighting the limited understanding of this pathology (WOLK \& SOMERS, 2006).

Received February 27, 2007

Address for correspondence:

ANA ANDRÉS

University of Barcelona, Department of Methodology for the Behavioural Sciences

Passeig Vall d'Hebron, 171, 08035 Barcelona, Spain

E-mail: anaandres@ub.edu

0138-9130/US \$20.00

Copyright (C) 2007 Akadémiai Kiadó, Budapest

All rights reserved 
The Transtheoretical Model (TTM) of behaviour change (DICLEMENTE \& Prochaska, 1982; Prochaska \& DiClemente, 1983; Prochaska et al., 1992a) emphasises the role of motivation, and is currently one of the most promising models in terms of understanding and promoting behaviour change related to the acquisition of healthy lifestyles. This model integrates emotional, cognitive and behavioural processes, as well as principles of change from the main theories of psychotherapy and health psychology (JORDAN et al., 2002), and has proven to be a useful basis for evaluating and monitoring change.

Although the model was initially applied in the context of people's attempts to give up smoking (Diclemente \& PROCHASKA, 1982; PROCHASKA \& DiclemenTE, 1983; DICLEMENTE et al., 1985; PROCHASKA et al., 1988), it soon become used in other areas and the same pattern of change was revealed across the stages for a wide range of problems (PROCHASKA, 1994; PROCHASKA et al., 1994). Recent studies have shown that the stages of change model can be applied to the treatment of eating disorders and for weight loss (WILSON \& SCHLAM, 2004). Its application has also spread to various issues associated with obesity: eating low fat foods, weight control, diabetes, eating fruit and vegetables, and doing physical exercise (MIILUNPALO et al., 2000; SIERO et al., 2000; STEPTOE et al., 2000; FEINSTEIN \& FEINSTEIN, 2001; KIRK et al., 2001).

The present report describes a bibliometric study of TTM application in the area of obesity. Bibliometrics is a powerful tool for evaluating scientific output (ROVIRA et al., 2000) and is widely used as a quantitative method for studying productivity by country, research area or institution (HE et al., 2005). Consequently, the present study offers an extensive review of scientific output with respect to what is currently one of the most influential theoretical models in the area of health psychology applied to the specific problem of obesity.

\section{Methods}

\section{Data collection}

The bibliographic search was conducted during 2005 in the databases of the ISI Web of Knowledge (2005).

The criteria for study selection were based on the key words "Transtheoretical Model", including all articles published in journals prior to 2005. It yielded a total of 437 articles. In order to restrict the study to articles related to the problem of obesity, a content analysis of the abstracts was then conducted.

Finally, the study sample was restricted to those articles referring to obesity and excess weight, as well as those concerning behaviour associated with this problem. Therefore, studies aimed at promoting physical exercise or healthy lifestyles in both the general population and patients with cardiovascular disorders or diabetes were also included. By applying these criteria a total of 139 articles were collected. 
Analysis

The articles were tabulated using SPSS v.11.01 (2001) and the following variables were coded: year of publication, number of authors contributing to the study, their names, institution and country to which they belong, and the journal in which the article was published.

Lotka's law (LOTKA, 1926) is a useful method for analysing author productivity. Lotka discovered that for a period of time greater than ten years, the more articles produced by an author the more likely he or she is to produce others. Therefore, productivity is related not to the number of articles published by an author but to its logarithm. The formula of Lotka's law states that $y_{x}=c \times x^{-n}$, whereby the expected frequency of the number of authors $(y)$ with a given number of publications $(x)$ can be obtained by calculating the constant $c$ and the exponent $n$. The calculation of $n$ is given by the following formula:

$$
n=\frac{N \sum X Y-\sum X \sum Y}{N \sum X^{2}-\left(\sum X\right)^{2}}
$$

where $N$ is the number of data pairs included in the analysis, and $X$ and $Y$ are, respectively, the logarithms of $x$ (number of articles) and $y$ (number of authors). The value of $n$ can be used to calculate $c$ using the formula:

$$
C=\frac{1}{\sum 1 / x^{n}}
$$

Finally, whether or not the expected frequencies fit the theoretical distribution can be checked by applying the non-parametric Kolmogorov-Smirnov (K-S) test. This requires the calculation of the critical value (c.v.), using the formula:

$$
c . v .=\frac{1.63}{\left(\sum y+\left(\sum y / 10\right)^{1 / 2}\right)^{1 / 2}}
$$

Lotka's law will be said to apply in the event that the maximum difference $\left(D_{\max }\right)$ between the expected and obtained frequencies is less than the critical value.

The mathematical model developed by BRADFORD $(1934,1948)$ is applicable to the scattering of articles in journals. Bradford's law is based on the idea that all the journals for a given scientific subject area can be distributed in concentric zones of decreasing productivity. The number of zones is usually fixed at three, each one containing a constant number of articles. However, the number of journals grows in a constant and multiplicative way from one zone to the next, according to the distribution $1, n, n^{2}$. Consequently, there will be a central core of highly productive journals surrounded by more peripheral zones containing journals with fewer publications in the given area. 
To analyse whether this law is applicable to the data obtained it is necessary to calculate Bradford's constant $k$ by means of the following formula:

$$
k=\left(1.781 \times Y_{m}\right)^{1 / P}
$$

where $Y_{m}$ is the number of studies published by the most productive journal and $P$ is the number of zones across which the journals are distributed. It is usual for $P$ to be fixed at three.

By comparing obtained and expected values of $k$ it is possible to check whether or not the obtained values fit with those predicted by the law.

The distribution can be represented graphically by means of a Bradford-Zipf plot (BROOKES, 1969), which represents the cumulative frequency of studies published by the journals in order of decreasing productivity. The resulting graph shows, initially, an exponential growth of output followed by linear growth.

Finally, Leimkuhler's formula (LEIMKHULER, 1967) can be used to calculate the equation that fits the Bradford curve. Its mathematical expression is:

$$
R(r)=a \log _{e}(1+b r)
$$

where $R(r)$ refers to the cumulative articles produced by journals in the different ranges (between 1 and $r$ ). The value of $a$ can be obtained from the formula $a=y_{o} / \log _{e} k$, where $y_{o}$ is the constant number of articles of each group, while $b=(k-1) / r_{o}$.

\section{Results}

\section{Year of publication}

Although the Transtheoretical Model of Change was first applied in the area of smoking in 1982, it was not extended to issues related to obesity until 1991 (Figure 1). However, the contribution of studies between this date and 1996 is of little relevance. Growing interest in this subject matter can be seen after 1997, when the number of studies published increases considerably up to the present day.

Observation of the temporal evolution of output with respect to the different issues related to obesity reveals a number of differences between them (Figure 2). While the practice of physical exercise is the area to which the model has been most frequently and was first - applied, there has been less interest in applying it to overweightness and obesity. 
A. ANDRÉS et al.: The Transtheoretical Model and obesity

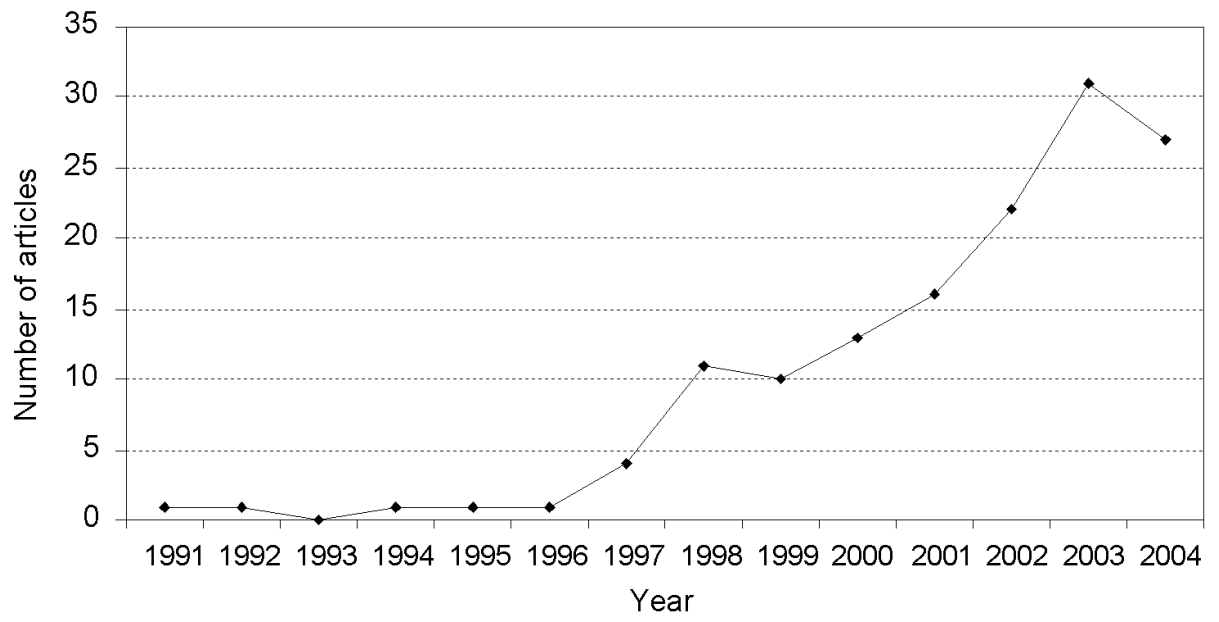

Figure 1. Temporal evolution of the number of publications

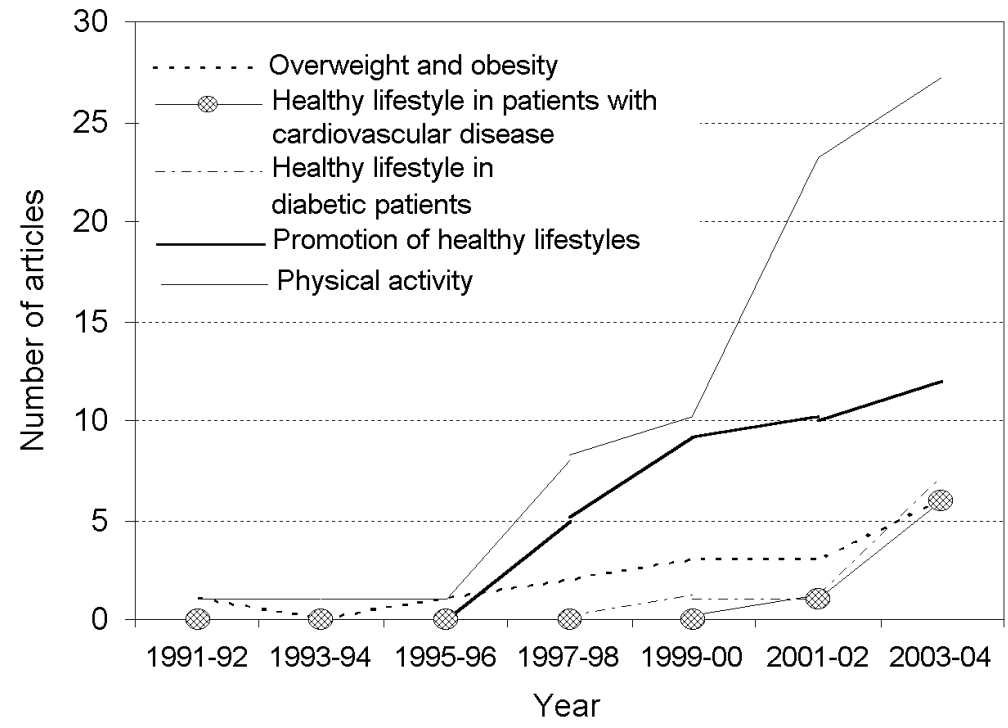

Figure 2. Temporal evolution of the number of articles according to subject area 
A. ANDRÉS et al.: The Transtheoretical Model and obesity

\section{Number of authors}

The number of authors contributing to articles ranges between 1 and 11, although it is most common ( $40.3 \%$ of cases) for there to be two or three authors per article (Figure 3 ). The mean number of contributors is 3.9 authors, with a standard deviation of 2.37 .

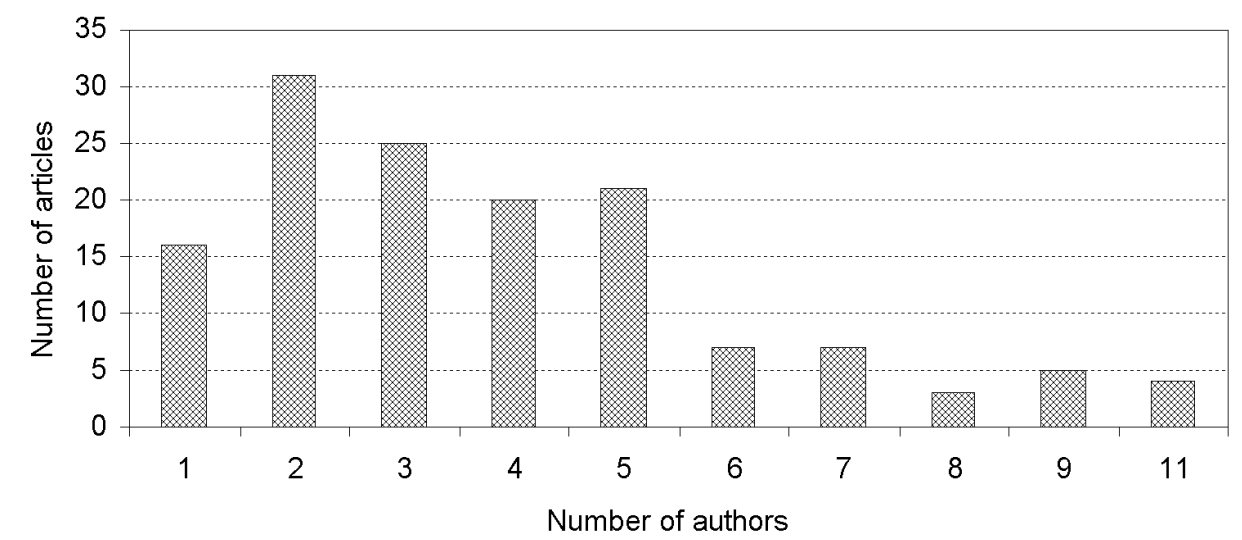

Figure 3. Number of authors contributing to the publications

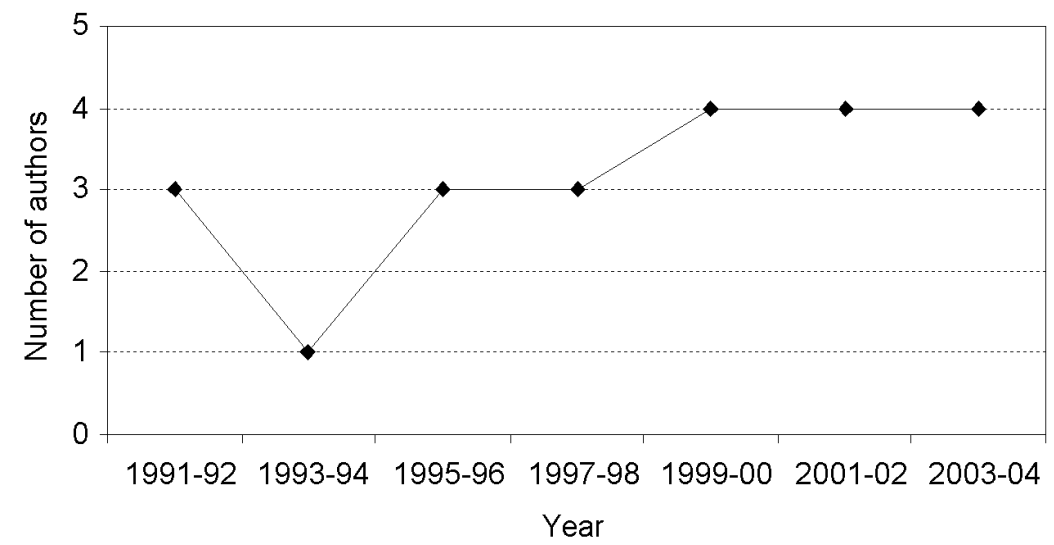

Figure 4. Temporal evolution of the number of authors

Observation of the temporal evolution of the mean number of authors contributing to articles (Figure 4) reveals that up to the end of the 1990s there tended to be three 
authors, whereas since then the figure has increased to four. It should be noted that between 1993 and 1994 there was only one article published, and therefore the mean is not representative of this period; this could account for the anomalous value obtained.

\section{Authors}

The total number of articles collected includes the names of 396 authors. However, given that some of them had published on more than one occasion the total number of contributions rises to 544 .

Author productivity is shown in Table 1, where it can be seen that the large majority of them $(80 \%)$ contribute to only one study.

Table 1. Author productivity

\begin{tabular}{ccc}
\hline Number of articles & Number of authors & $\%$ \\
\hline 1 & 317 & 80.05 \\
2 & 49 & 12.37 \\
3 & 16 & 4.04 \\
4 & 6 & 1.52 \\
5 & 3 & 0.76 \\
6 & 1 & 0.25 \\
7 & 1 & 0.25 \\
8 & 2 & 0.51 \\
13 & 1 & 0.25 \\
\hline
\end{tabular}

However, there is a small group of highly prolific authors (Table 2), whose output accounts for approximately $15 \%$ of the total number of contributions.

Table 2. Most productive authors

\begin{tabular}{lccc}
\hline Author & Frequency & $\%$ & Accumulated \% \\
\hline Nigg, CR & 13 & 2.39 & 2.39 \\
Greene, GW & 8 & 1.47 & 3.86 \\
Marcus, BH & 8 & 1.47 & 5.33 \\
Cardinal, BJ & 7 & 1.29 & 6.62 \\
Prochaska, JO & 6 & 1.10 & 7.72 \\
Mutrie, N & 5 & 0.92 & 8.64 \\
Rossi, JS & 5 & 0.92 & 9.56 \\
Rossi, SR & 5 & 0.92 & 10.48 \\
Clark, PG & 4 & 0.74 & 11.21 \\
Kosma, M & 4 & 0.74 & 11.95 \\
Padula, C & 4 & 0.74 & 12.68 \\
Pinto, BM & 4 & 0.74 & 13.42 \\
Ruggiero, L & 4 & 0.74 & 14.15 \\
Sallis, JF & 4 & 0.74 & 14.89 \\
\hline
\end{tabular}


In order to conduct a more exhaustive analysis of productivity, Lotka's law was applied. The data shown in Table 1 gave a value for the constant $n$ of 2.48 .

As the critical value obtained $(c . v .=0.0813)$ is greater than the maximum distance between the obtained and expected frequencies $\left(D_{\max }=0.044\right)$, as shown in Table 3 , it is concluded that the study data fit Lotka's law.

Table 3. Application of Lotka's law

\begin{tabular}{ccccccccccc}
\hline$X$ & $y$ & $X=\lg x$ & $Y=\lg y$ & $X^{2}$ & $X Y$ & $y / \sum y$ & $\sum\left(y / \sum y\right)$ & $f_{e}=C\left(1 / x^{n}\right)$ & $\sum f_{e}$ & $D$ \\
\hline 1 & 317 & 0.000 & 2.501 & 0.000 & 0.000 & 0.801 & 0.801 & 0.756 & 0.756 & 0.044 \\
2 & 49 & 0.301 & 1.690 & 0.091 & 0.509 & 0.124 & 0.924 & 0.136 & 0.892 & 0.033 \\
3 & 16 & 0.477 & 1.204 & 0.228 & 0.575 & 0.040 & 0.965 & 0.050 & 0.941 & 0.024 \\
4 & 6 & 0.602 & 0.778 & 0.362 & 0.468 & 0.015 & 0.980 & 0.024 & 0.965 & 0.014 \\
5 & 3 & 0.699 & 0.477 & 0.489 & 0.333 & 0.008 & 0.987 & 0.014 & 0.979 & 0.008 \\
6 & 1 & 0.778 & 0.000 & 0.606 & 0.000 & 0.003 & 0.990 & 0.009 & 0.988 & 0.002 \\
7 & 1 & 0.845 & 0.000 & 0.714 & 0.000 & 0.003 & 0.992 & 0.006 & 0.994 & -0.002 \\
8 & 2 & 0.903 & 0.301 & 0.816 & 0.272 & 0.005 & 0.997 & 0.004 & 0.999 & -0.001 \\
13 & 1 & 1.114 & 0.000 & 1.241 & 0.000 & 0.003 & 1.000 & 0.001 & 1.000 & 0.000 \\
& & & & & & & & & & \\
\hline
\end{tabular}

\section{Institutions and countries}

The contributing authors belong to various institutions: universities, hospitals, private research centres and government departments, among others. The total number of institutions was 176, and Table 4 shows those whose authors have contributed to at least five articles.

Table 4. Most productive institutions

\begin{tabular}{lcc}
\hline Institution & Frequency & $\%$ \\
\hline University of Rhode Island & 23 & 16.55 \\
Miriam Hospital and Brown University Medical School & 10 & 7.19 \\
Oregon State University & 10 & 7.19 \\
Stanford University & 6 & 4.32 \\
Louisiana State University & 5 & 3.60 \\
San Diego State University & 5 & 3.60 \\
University of Glasgow & 5 & 3.60 \\
University of Hawaii at Manoa & 5 & 3.60 \\
University of Maryland & 5 & 3.60 \\
University of Texas & 5 & 3.60 \\
\hline
\end{tabular}

Closely related to the most productive institutions are the countries to which they belong. Authors from a total of sixteen countries have published articles on this subject, and they are distributed as shown in Table 5. The majority of articles (over 70\%) 
included at least one author from the USA, followed by the UK, which has contributed to $11 \%$ of articles.

Table 5. Output by country

\begin{tabular}{lcc}
\hline Country & Frequency & $\%$ \\
\hline USA & 100 & 71.94 \\
UK & 16 & 11.51 \\
Canada & 10 & 7.19 \\
Australia & 8 & 5.76 \\
Finland & 5 & 3.60 \\
Netherlands & 4 & 2.88 \\
China & 3 & 2.16 \\
Japan & 3 & 2.16 \\
Germany & 2 & 1.44 \\
Korea & 2 & 1.44 \\
Switzerland & 2 & 1.44 \\
Austria & 1 & 0.72 \\
Ireland & 1 & 0.72 \\
New Zealand & 1 & 0.72 \\
\hline
\end{tabular}

\section{Journals}

The 139 publications included in the analysis are distributed across a total of 68 journals from different fields, the most important being medicine, psychology, sport, nutrition and nursing. Given the large number of journals with an interest in the health field the publication of articles shows a wide scatter. However, Health Education Research and Preventive Medicine stand out as the two journals to have published most widely about the application of the TTM to obesity. Table 6 shows the journals which have published three or more articles about this issue.

Table 6. Number of publications of the most productive journals

\begin{tabular}{lccc}
\hline Journal & Frequency & $\%$ & Accumulated \% \\
\hline Health Education Research & 12 & 8.63 & 8.63 \\
Preventive Medicine & 9 & 6.47 & 15.11 \\
American Journal of Health Promotion & 7 & 5.04 & 20.14 \\
Annals of Behavioral Medicine & 7 & 5.04 & 25.18 \\
American Journal of Preventive Medicine & 5 & 3.60 & 28.78 \\
American Journal of Health Behavior & 5 & 3.60 & 32.37 \\
Medicine and Science in Sports and Exercise & 4 & 2.88 & 35.25 \\
Public Health Nursing & 4 & 2.88 & 38.13 \\
Journal of Nutrition Education and Behavior & 3 & 2.16 & 40.29 \\
Psychology \& Health & 3 & 2.16 & 42.45 \\
Journal of the American Dietetic Association & 3 & 2.16 & 44.60 \\
Research Quarterly for Exercise and Sport & 3 & 2.16 & 46.76 \\
British Journal of Health Psychology & 3 & 2.16 & 48.92 \\
Diabetes Care & 3 & 2.16 & 51.08 \\
Journal of Human Nutrition and Dietetics & 3 & 2.16 & 53.24 \\
\hline
\end{tabular}


By applying Bradford's law it was possible to analyse how the journals are distributed according to their productivity. In this case, Bradford's $k$ constant has a value of 2.78, which yields the journal distribution shown in Table 7 .

Table 7. Bradford's distribution

\begin{tabular}{cccc}
\hline Zones & Number of journals & Number of articles & $k$ \\
\hline 1 & 6 & 45 & - \\
2 & 16 & 43 & 2.67 \\
3 & 46 & 51 & 2.875 \\
\hline
\end{tabular}

The similarity of the different values of $k$, and between these and the calculated Bradford's constant indicates that the data show a good fit with Bradford's law.

In addition, the Bradford-Zipf plot (Figure 5) represents graphically the distribution of the cumulative frequency of articles with respect to journals, the latter being ordered in terms of productivity.

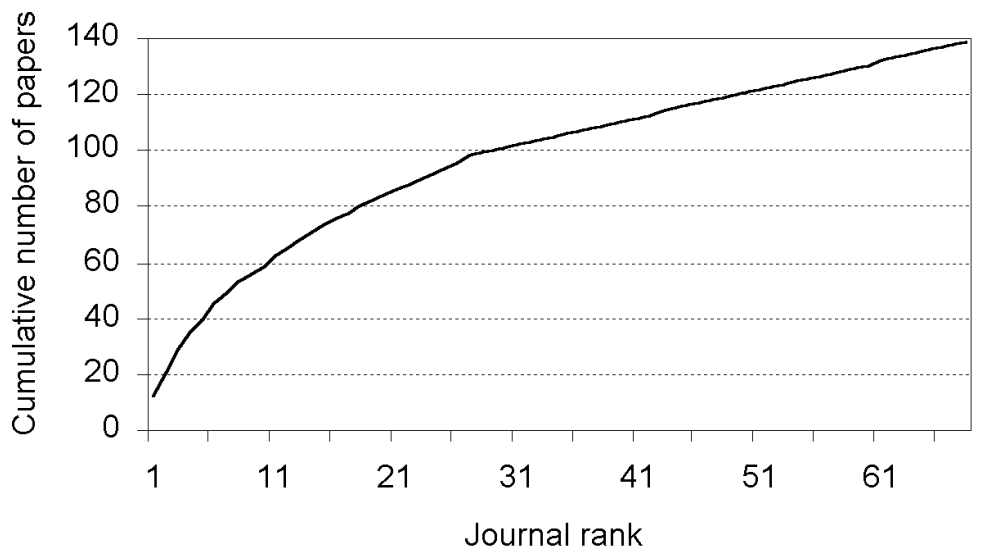

Figure 5. Bradford-Zipf plot

Finally, Leimkuhler's formulation gives the logarithmic formula corresponding to the previous graph by calculating the values $a$ and $b$. Therefore, in this specific case the formula explaining the distribution of articles according to journals is:

$$
R(r)=44.99 \log _{e}(1+0.3017 r)
$$

where $R$ is the cumulative number of articles published by the journals across the different ranges $r$. 


\section{Discussion}

Treatments geared toward weight loss imply an across-the-board change in lifestyle, as long-term achievements require the modification of attitudes, beliefs and behaviours regarding food and physical activity (HILL \& WYATT, 2002). It is therefore an active process in which the person must make a considerable effort to change old habits (ROLLNICK, 1996), this being one reason why obesity treatments do not always achieve good outcomes.

As a result of the empirical support it has received (PROCHASKA et al., 1992b; PROCHASKA et al., 1994; HORWATH, 1999) the Transtheoretical Model could now be considered a useful approach for the evaluation and treatment of obesity. Due to the extensive literature about this theoretical model, there was a need to carry out a bibliometric study to assess the scientific output related to obesity.

The present study offers a first approximation to the issue of scientific productivity in this field. The results obtained reveal a growing interest in applying the Transtheoretical Model to both the treatment of obesity and its prevention through promoting healthy lifestyles in both the general population and at-risk groups. In the analyses conducted, the mean number of contributing authors ranges from three to four, this being a common figure in other applied fields of psychology. In terms of author output it should be highlighted that the distribution fits Lotka's law, a small group of authors being responsible for most of the output. These authors mostly belong to the University of Rhode Island, and consequently the USA is the country which publishes most articles on this subject. With respect to the distribution of publications across journals we found that journal output fits the model proposed by Bradford. In this regard, the core from which a certain influence is exerted over the rest of the scientific community is comprised of two journals: Health Education Research and Preventive Medicine. These two account for over $15 \%$ of the publications included in the present study.

The limitations of this study are related to the methodology used to carry out the bibliographic search, that is, the criteria for including documents and the databases chosen for the search. Although the articles chosen had to be strictly related to the area under study (obesity according to the Transtheoretical Model) it is possible that other related articles may have been omitted if the key words used did not feature in their abstract or title, or if the article itself was not cited in the databases used (ISI Web of Knowledge).

This study is supported by the "Ministerio de Ciencia y Tecnología" of Spain and the FEDER (SEJ2005-09144-C02-02) and by the "Generalitat de Catalunya" (2006FIC 00146 and 2005SGR00365). 


\section{References}

BRADFORD, S. C. (1934), Sources of information on specific subjects. Journal of Information Science, 10 : 176-180. Reprinted from (1934), Engineering, $137: 85-88$.

BRADFORD, S. C. (1948), Documentation, Crosby Lockwood Sons Ltd., London.

BRoOKES, B. C. (1969), Bradford's law and the bibliography of science, Nature, 224 : 953-956.

Diclemente, C. C., ProchaskA, J. O. (1982), Self-change and therapy change of smoking behavior: A comparison of processes of change in cessation and maintenance, Addictive Behaviors, $7: 133-144$.

Diclemente, C. C., Prochaska, J. O., Gibertini, M. (1985), Self-efficacy and the stages of self-change of smoking, Cognitive Therapy and Research, $9: 181-200$.

Feinstein, R. E., Feinstein, M. S. (2001), Psychotherapy for health and lifestyle change, Journal of Clinical Psychology, $57:$ 1263-1275.

He, T., ZhAng, J., Teng, L. (2005), Basic research in biochemistry and molecular biology in China: A bibliometric analysis, Scientometrics, $62: 249-259$.

HiLl, J., WyatT, H. (2002), Outpatient management of obesity: a primary care perspective, Obesity Research, $10: 124 \mathrm{~S}-130 \mathrm{~S}$

Horwath, C. C. (1999), Applying the transtheoretical model to eating behaviour change: challenges and opportunities, Nutrition Research Reviews, $12: 281-317$

INSTITUTE FOR SCIENTIFIC INFORMATION (ISI) (2005), Thomson Scientific, Philadelphia, PA, USA.

Jordan, P. J., Nigg, C. R., Norman, G. J., Rossi, J. S., Benisovich, S. V. (2002), Does the transtheoretical model need an attitude adjustment? Integrating attitude with decisional balance as predictors of stage of change for exercise. Psychology of Sport and Exercise, $3: 65-83$.

Kirk, A. F., Higgins, L. A., Hughes, A. R., Fishert, B. M., Mutrie, N., Hillis, S., Macintyre, P. D. (2001), A randomized, controlled trial to study the effect of exercise consultation on the promotion of physical activity in people with type 2 diabetes: a pilot study, Diabetic Medicine, 18 : 877-882.

LEIMKUHLER, F. F. (1967), The Bradford distribution, Journal of Documentation, 23 : 197-207.

LOTKA, A. J. (1926), The frequency distribution of scientific productivity, Journal of the Washington Academy of Sciences, $16: 317-323$.

Millunpalo, S., Nupponen, R., Laitakari, J., Marttila, J., Paronen, O. (2000), Stages of change in two modes of health-enhancing physical activity: methodological aspects and promotional implications, Health Education Research, $15: 435-448$.

ProchASKA, J. O. (1994), Strong and weak principles for progressing from precontemplation to action on the basis of twelve problem behaviours, Health Psychology, $13: 47-51$

Prochaska, J. O., Diclemente, C. C. (1983), Stages and processes of self-change of smoking: toward an integrative model of change, Journal of Consulting and Clinical Psychology, 51 : 390-395.

Prochaska, J. O., Diclemente, C. C., Norcross, J. C. (1992a), In search of how people change: Applications to addictive behaviours, American Psychologist, 47 : 1102-1114.

Prochaska, J. O., Diclemente, C. C., Velicer, W. F., FAVA, J. (1988), Measuring processes of change: Applications to the cessation of smoking, Journal of Consulting and Clinical Psychology, $56: 520-528$.

Prochaska, J. O., Norcross, J. C., Fowler, J. L., Follnick, M. J., Abrams, D. B. (1992b), Attendance and outcome in a work site weight control program: Processes and stages of change as process and predictor variables, Addictive Behaviors, $17: 35-45$.

Prochaska, J. O., Velicer, W. F., Rossi, J. S., Goldstein, M. G., Marcus, B. H., Rakowski, W., Fiore, C., Harlow, L. L., Reeding, C. A., Rosenbloom, D., Rossi, S. R. (1994), Stages of change and decisional balance for 12 problem behaviors, Health Psychology, $13: 39-46$.

RollniCK, S. (1996). Behaviour change in practice: targeting individuals, International Journal of Obesity, $20:$ S22-S26.

Rovira, L., SEnRA, P., JOU, D. (2000), Bibliometric analysis of physics in Catalonia: Towards quality consolidation? Scientometrics, $49: 233-256$

Siero, F. W., Broer, J., Bemelmans, W. J. E., Meyboom-De-Jong, B. M. (2000), Impact of group nutrition education and surplus value of Prochaska-based stage-matched information on health-related cognitions and on Mediterranean nutrition behavior, Health Education Research, 15 : 635-647. 
SPSS, 11.0.1. (1989-2001), SPSS Inc.

Steptoe, A., RinK, E., KerRy, S. (2000), Psychosocial predictors of changes in physical activity in overweight sedentary adults following counselling in primary care, Preventive Medicine, 31 : 183-194.

Wilson, G. T., Schlam, T. R. (2004), The transtheoretical model and motivational interviewing in the treatment of eating and weight disorders, Clinical Psychology Review, 24 : 361-378.

Wolk, R., SOMERS, V. K. (2006), Obesity-related cardiovascular disease: implications of obstructive sleep apnea, Diabetes, Obesity and Metabolism, 8 (3) : 250-260.

WORLD HEALTH ORGANIZATION (2000), Obesity: preventing and managing the global epidemic. Report of a WHO consultation, World Health Organization Technical Report Series, $894: 1-253$. 